08.1

\title{
Особенности зарождения и роста нитевидных нанокристаллов InGaN на подложках SiC/Si методом хлорид-гидридной эпитаксии
}

\author{
(ㄷ С.А. Кукушкин ${ }^{1,2}$, А.В. Осипов ${ }^{1,2}$, А.В. Редьков ${ }^{1,2}$, В.М. Стожаров ${ }^{3}$, Е.В. Убыйвовк ${ }^{1}$, \\ Ш.Ш. Шарофиидинов ${ }^{4}$ \\ ${ }^{1}$ Санкт-Петербургский государственный университет, Санкт-Петербург, Россия \\ ${ }^{2}$ Институт проблем машиноведения РАН, Санкт-Петербург, Россия \\ ${ }^{3} \mathrm{OОО} \mathrm{„Научно-технический} \mathrm{центр} \mathrm{„Новые} \mathrm{технологии“,} \mathrm{Санкт-Петербург,} \mathrm{Россия}$ \\ ${ }^{4}$ Физико-технический институт им. А.Ф. Иофффе РАН, Санкт-Петербург, Россия \\ E-mail: sergey.a.kukushkin@gmail.com
}

Поступило в Редакцию 20 октября 2021 г.

В окончательной редакции 20 октября 2021 г.

Принято к публикации 15 ноября 2021 г.

\begin{abstract}
Исследован рост слоев InGaN на гибридных подложках $\mathrm{SiC} / \mathrm{Si}$ ориентаций (100), (110) и (111) методом хлорид-гидридной эпитаксии при температуре, заведомо превышающей температуру распада InN на атомы азота и металлический In $\left(1000^{\circ} \mathrm{C}\right)$. На подложках ориентаций $(110)$ и (111) обнаружено формирование нитевидных нанокристаллов InGaN. Исследованы форма и механизмы роста нитевидных нанокристаллов. Показано, что нанокристаллы зарождаются на поверхности (111) только внутри $V$-дефектов, образующихся в местах выхода винтовых дислокаций на поверхность. На поверхности (110) нанокристаллы образуются только на пьедесталах, возникающих в процессе роста пленки. Дано объяснение различия механизмов роста нанокристаллов на подложках разной ориентации.
\end{abstract}

Ключевые слова: InGaN, гетероструктуры, $\mathrm{SiC}$ на $\mathrm{Si}$, кремний, нитевидные нанокристаллы, наноструктуры, метод замещения атомов.

DOI: 10.21883/PJTF.2022.04.52080.19056

Хорошо известно, насколько трудно повысить эффективность оптоэлектронных устройств, работающих в желто-зеленом диапазоне света и использующих гетероструктуры InGaN с высокой долей содержания индия. Прежде всего это связано со сложностью получения низкодефектных пленок InGaN. Для решения данной проблемы авторы ряда работ [1-3] предлагают при создании гетероструктур вместо эпитаксиальных сплошных слоев, содержащих индий, использовать нитевидные нанокристаллы (ННК), поскольку в самих нанокристаллах практически не образуются дислокации несоответствия [4]. Отметим, что основная часть работ посвящена росту методами молекулярно-пучковой эпитаксии или газофазной эпитаксии из металлоорганических соединений. Однако еще сложнее вырастить эпитаксиальные слои InN методом хлорид-гидридной эпитаксии (ХГЭ) [5-10], поскольку при давлении реакционных газов, близком к атмосферному, и температурах, превышающих $500^{\circ} \mathrm{C}$, InN распадается на металлический индий и молекулы азота [8]. В свою очередь в [11] было обнаружено, что In оказывает существенное влияние на скорость роста пленок $\mathrm{AlGaN}$ и их структурные характеристики. В связи с этим целью настоящей работы является исследование влияния индия на рост пленок $\mathrm{GaN}$ методом ХГЭ при температурах, значительно превышающих температуру распада InN. Предполагалось использовать индий как своеобразный катализатор, который может оказать кратковременное воздействие на процесс нуклеации $\mathrm{GaN}$, а затем будет удален из зоны реакции.
Для экспериментов использовались подложки кремния $p$-типа ориентаций (100), (110) и (111). Сначала на этих подложках методом [12] были синтезированы слои nano-SiC/Si при следующих условиях: $T=1290^{\circ} \mathrm{C}$, $P=0.5$ Torr, потоки $\mathrm{SiH}_{4}$ и $\mathrm{CO}-12$ и $0.25 \mathrm{sccm}$ соответственно, $t=20 \mathrm{~min}$. Затем на них методом ХГЭ $[13,14]$ при температуре $1000^{\circ} \mathrm{C}$ в течение $3 \mathrm{~min}$ наносился буферный слой AIN. После этого в ростовую камеру подавалась газовая смесь хлоридов галлия, индия $(\mathrm{Ga} / \mathrm{In}=80: 20)$ и $\mathrm{HCl}$ в течение $3 \mathrm{~min}$. Условия роста на подложках всех ориентаций были идентичными. После синтеза образцы исследовались методами растровой электронной микроскопии (РЭМ) (Tescan Mira 3 с приставкой энергодисперсионной спектроскопии (EDS)), рамановской спектроскопии (Witec Alpha 300R) и рентгеновской дифрактометрии (ДРОН-8).

Исследования показали, что при росте $\mathrm{GaN}$ с добавкой InN на подложках ориентаций (110) и (111) на поверхности образовались нитевидные кристаллы (рис. 1). При росте $\mathrm{GaN}$ в этих же условиях, но в отсутствие индия образования нитевидных кристаллов ранее не наблюдалось $[13,14]$. На подложке ориентации (100) образования ННК не обнаружено. Кроме того, на подложках ориентаций (110) и (111) в слоях присутствовало исчезающе малое количество InN. EDSизмерения и рамановские спектры не показали наличия InN в слоях. Только методом рентгеновской дифрактометрии удалось выявить присутствие фаз, содержащих InN. На подложках ориентации (100) InN не был 
$a$
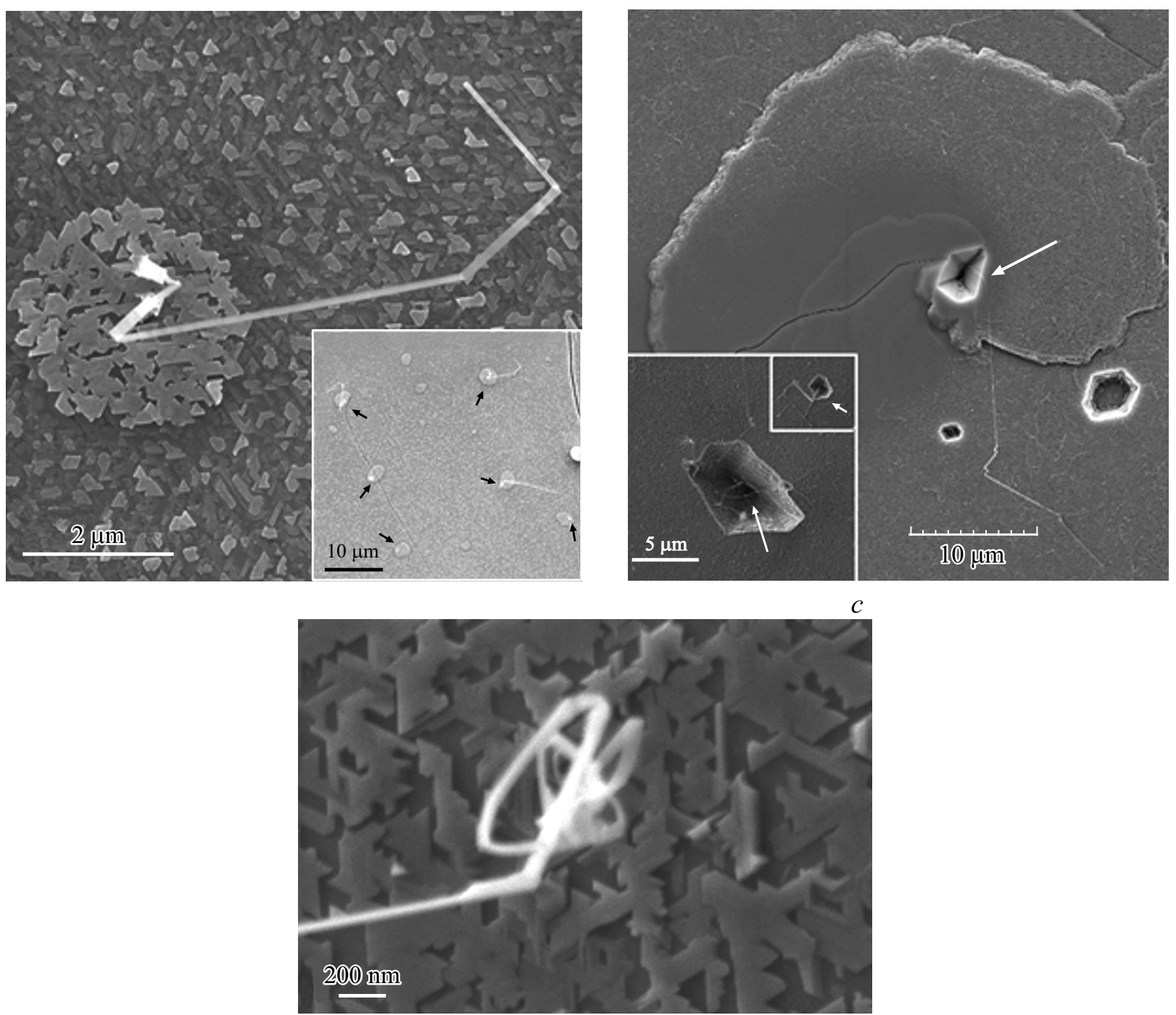

Рис. 1. РЭМ-изображение механизма роста нитевидных нанокристаллов на пьедесталах на поверхности InGaN на подложке с ориентацией $(110)(a)$ и на месте выхода дислокации на подложке $(111)(b, c)$. Вставка на части $а$ демонстрирует область с пьедесталами, на каждом из которых растет по отдельному нанокристаллу. На части $c$ представлена начальная стадия роста „закрученного“ ННК.

обнаружен вовсе, во всяком случае в пределах чувствительности приборов. На рис. 2 в качестве примера приведена дифрактограмма образца, выращенного на подложке ориентации (111). По смещению брэгговских углов для гексагональной оси $c$ были оценены сверху упругие напряжения: $\sigma_{\mathrm{InN}} \approx-4 \mathrm{GPa}$ и $\sigma_{\mathrm{GaN}} \approx-12 \mathrm{GPa}$, тогда как для подложки (110) они оказались меньше и составили $\sigma_{\mathrm{InN}} \approx-0.78 \mathrm{GPa}, \sigma_{\mathrm{GaN}} \approx 3 \mathrm{GPa}$. Вдоль оси $c$ InN растянут, т.е. вдоль оси $a$ происходит сжатие. Отметим, что эти оценки являются достаточно грубыми, поскольку в системе присутствуют не чистые вещества, а твердые растворы $\operatorname{In}_{x} \mathrm{Ga}_{1-x} \mathrm{~N}$. Отметим также, что знаки напряжений на подложке (110) у $\mathrm{InN}$ и $\mathrm{GaN}$ различаются, что существенно меняет природу роста пленок по сравнению со случаем подложки (111).
На рис. $1, b$ приведено изображение поверхности подложки ориентации (111). На ней образуются ННК ленточного типа, растущие из $V$-дефектов. Их образование похоже на раскручивание сжатой тонкой пружины, конец которой, высвобождаясь и имея момент вращения, начинает случайным образом вращаться, все более и более запутываясь и образуя клубок переплетенных нитевидных кристаллов. Подобный механизм реализуется за счет сжимающих напряжений и значительного различия этих напряжений в InN и $\mathrm{GaN}$. На поверхности пленки более крупный по сравнению с Ga атом In будет легко вступать в реакцию с $\mathrm{HCl}$ и испаряться. Лишь внутри $V$-дефектов, где практически все напряжения срелаксировали, он может находиться короткое время, а затем будет либо испаряться, либо образовывать на 


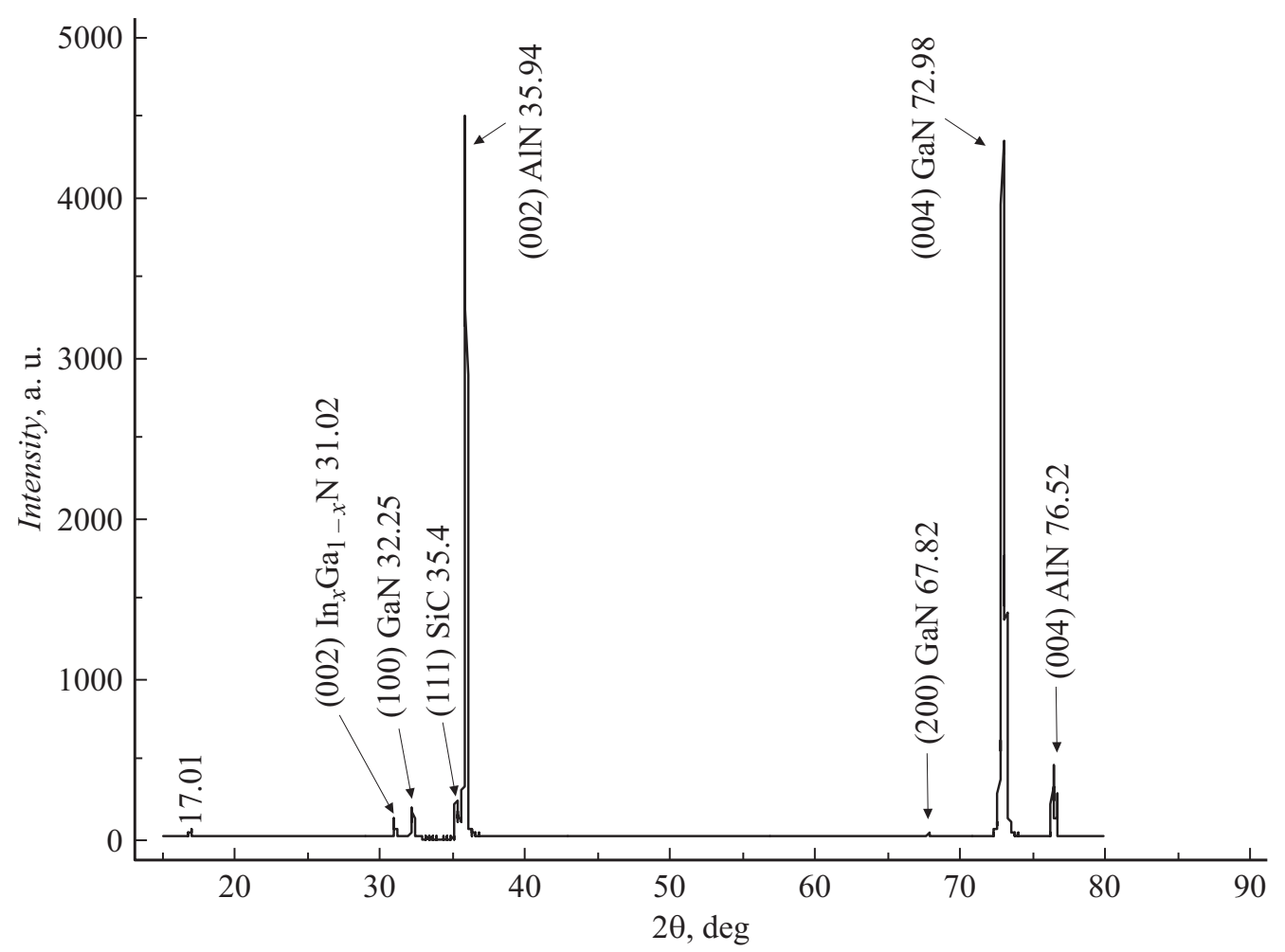

Рис. 2. Дифрактограмма образца InGaN, выращенного на подложке $\mathrm{SiC} / \mathrm{Si}$ (111).

поверхности стенок $V$-дефектов ростовые слои. Эти слои по мере их ,закручивания“ все больше и больше будут подвергаться сжатию, что в конечном счете приведет к отрыву их от стенок $V$-дефектов и дальнейшему свободному росту вдоль поверхности подложки. Образование $V$-дефектов в слое $\mathrm{GaN}$, как показано в [15], связано с образованием малоугловых границ зерен, приводящих к упругим деформациям, нарушению стехиометрического состава адатомов, из ансамбля которых растет пленка $\mathrm{GaN}$, и формированию дислокации. Впоследствии в этом месте реализуется слоисто-спиральный рост [16] $\mathrm{GaN}$, что хорошо видно по частично незаросшему верхнему слою, а само зарождение ННК происходит непосредственно возле или в ядре дислокации. Средняя длина ленточных нанокристаллов составляет $30-60 \mu \mathrm{m}$. Отметим, что рядом с ядром дислокации (но вне его) упругие напряжения максимальны. В ядре же наблюдается их резкая релаксация. Для оценки была измерена серия рамановских спектров пленки на различных расстояниях от ядра дислокации (рис. 3). По смещению одного из основных пиков $\operatorname{In}_{x} \mathrm{Ga}_{1-x} \mathrm{~N}$ $E_{2(\text { high })}\left(\sim 568 \mathrm{~cm}^{-1}\right.$ при $\left.x<0.05[17,18]\right)$ была сделана оценка упругих напряжений $\sigma$ (рис. 3 ) согласно формуле $\Delta \omega=4.3 \sigma\left[\mathrm{cm}^{-1} / \mathrm{GPa}\right][18]$. Вблизи ядра дислокации упругие напряжения достигают $0.88 \mathrm{GPa}$, тогда как вне области дислокации оценка дает $\sim 0.7 \mathrm{GPa}$. Отметим, что положение рамановской линии также зависит от мольной доли индия $x$ в составе твердого раствора, ввиду чего полученная оценка также является довольно грубой [17].

На поверхности подложки ориентации (110), как и на подложке ориентации (111), образовались ННК ленточного типа (рис. 1,a). Однако в случае (110) они зарождаются на поверхности сросшихся зародышей верхнего слоя GaN, образующих пьедесталы. Затравкой для нанокристаллов является один из зародышей, входящий в конгломерат (пьедестал). Отметим, что рост ННК на пьедесталах наблюдался в работе [19], однако в большинстве случаев размер пьедесталов был сопоставим с диаметром ННК. В данном случае диаметр сросшегося конгломерата (пьедестала) составляет величину порядка $2-3 \mu \mathrm{m}$, что значительно больше диаметра ННК. Ленточные ННК на поверхности (110) на начальном этапе роста не образуют переплетений. Они расположены вдоль поверхности подложки и имеют длинные прямые участки с резкими изломами общей длиной порядка $10 \mu \mathrm{m}$. Отметим, что нитевидные кристаллы, растущие по этому механизму, наблюдаются исключительно на пьедесталах (см. вставку на рис. $1, a)$. И этот механизм совершенно понятен с изложенной выше точки зрения. Действительно, на поверхности (110) в среднем по слою $\mathrm{GaN}$ упругие напряжения являются растягивающими. Образование конгломератов (пьедесталов) связано с дефектами в слое под ними. Упругие (растягивающие) напряжения приводят к тому, что состав паровой фазы над пьедесталом и над свободной поверхностью подложки различен. Большому атому In выгоднее адсорбироваться 


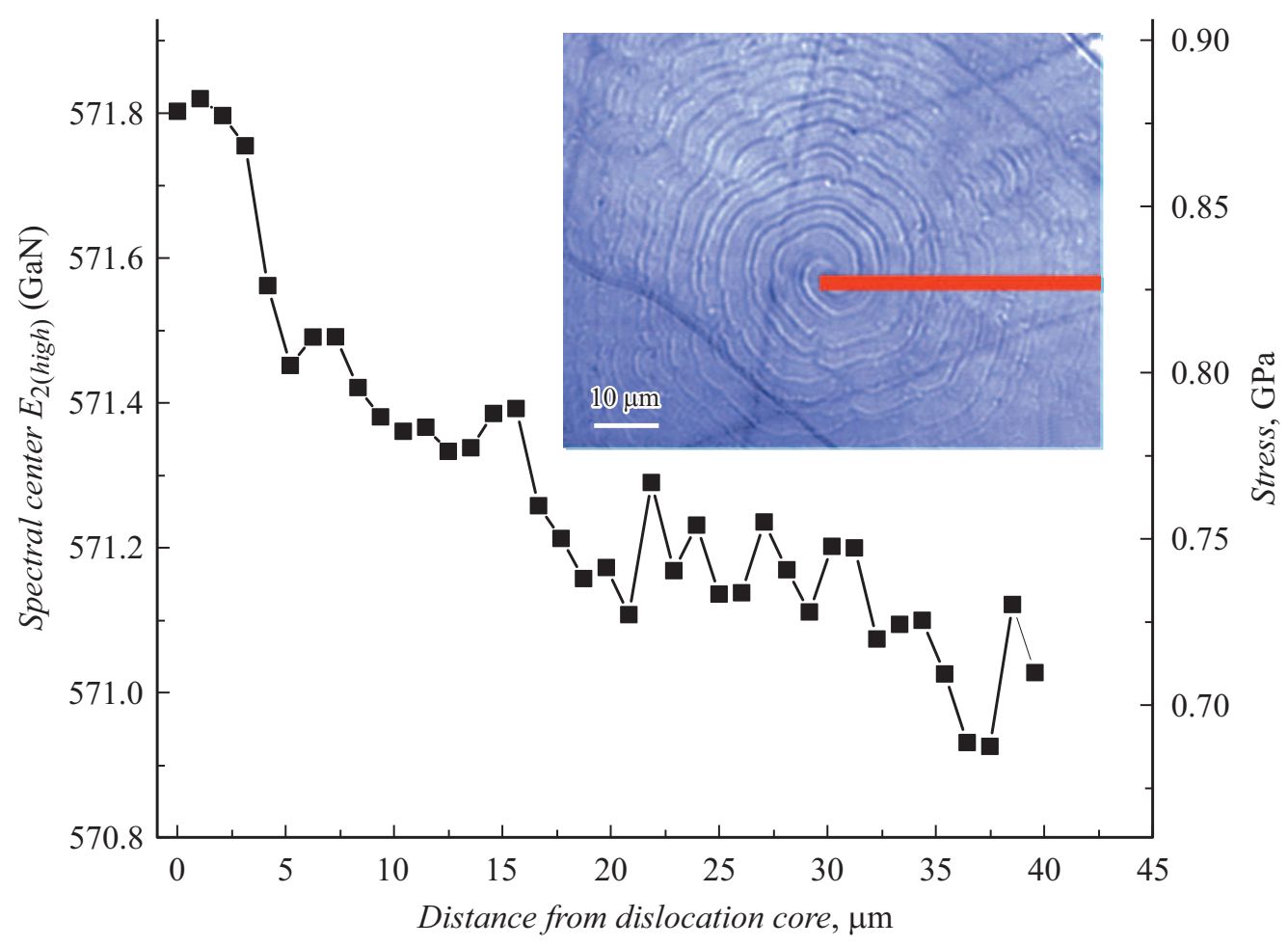

Рис. 3. Положение рамановской линии $E_{2(h i g h)}$ и полученная по нему оценка величины упругих напряжений на различных расстояниях от ядра дислокации. Измерения сделаны вдоль линии, отмеченной на вставке.

на поверхности пьедестала, что в конечном счете и проводит к зарождению ННК на его вершине.

Таким образом, в работе продемонстрирована реализация новых механизмов роста ННК при росте пленок $\mathrm{InGaN}$ методом ХГЭ на подложках $n a n o-\mathrm{SiC} / \mathrm{Si}$. Показано, что индий, добавленный в паровую фазу, играет роль катализатора, стимулирующего зарождение ННК.

\section{Благодарности}

Исследования проводились с использованием оборудования УНУ „Физика, химия и механика кристаллов и тонких пленок“ (ИПМаш РАН, Санкт-Петербург).

Авторы выражают благодарность демонстрационной лаборатории ООО „Тескан“ за содействие в электронномикроскопических исследованиях, а также А.С. Гращенко за помощь в приготовлении образца $\mathrm{SiC} / \mathrm{Si}$.

\section{Финансирование работы}

Работа выполнена при финансовой поддержке Российского научного фонда (грант № 19-72-30004).

\section{Конфликт интересов}

Авторы заявляют, что у них нет конфликта интересов.

\section{Список литературы}

[1] V.O. Gridchin, K.P. Kotlyar, R.R. Reznik, A.S. Dragunova, N.V. Kryzhanovskaya, V.V. Lendyashova, D.A. Kirilenko, I.P. Soshnikov, D.S. Shevchuk, G.G. Cirlin, Nanotechnology, 32 (33), 335604 (2021). DOI: 10.1088/1361-6528/ac0027

[2] E. Roche, Y. Andre, G. Avit, C. Bougerol, D. Castelluci, F. Reveret, G. Evelyne, F. Medard, J. Leymarie, T. Jean, V.G. Dubrovskii, A. Trassoudaine, Nanotechnology, 29 (46), 465602 (2018). DOI: 10.1088/1361-6528/aaddc1

[3] H. Hijazi, M. Zeghouane, J. Jridi, E. Gil, D. Castelluci, V.G. Dubrovskii, C. Bougerol, Y. Andre, A. Trassoudaine, Nanotechnology, 32 (15), 155601 (2021). DOI: $10.1088 / 1361-6528 / a b d b 16$

[4] В.О. Гридчин, Р.Р. Резник, К.П. Котляр, А.С. Драгунова, Н.В. Крыжановская, А.Ю. Серов, С.А. Кукушкин, Г.Э. Цырлин, Письма в ЖТФ, 47 (21), 32 (2021). DOI: 10.21883/PJTF.2021.21.51626.18894

[5] Y. Sato, S. Sato, J. Cryst. Growth, 144 (1-2), 15 (1994). DOI: 10.1016/0022-0248(94)90004-3

[6] H. Sunakawa, A. Atsushi Yamaguchi, A. Kimura, A. Usui, Jpn. J. Appl. Phys., 35 (11A), L1395 (1996). DOI: 10.1143/JJAP.35.L1395

[7] N. Takahashi, J. Ogasawara, A. Koukitu, J. Cryst. Growth, 172 (3-4), 298 (1997). DOI: 10.1016/S0022-0248(96)00751-8

[8] I. Grzegory, S. Krukowski, J. Jun, M. Bockowski, M. Wroblewski, S. Porowski, AIP Conf. Proc., 309 (1), 565 (1994). DOI: 10.1063/1.46099

[9] K. Hanaoka, H. Murakami, Y. Kumagai, A. Koukitu, J. Cryst. Growth, 318 (1), 441 (2011). DOI: $10.1016 /$ j.jcrysgro.2010.11.079 
[10] С.А. Кукушкин, А.В. Осипов, Письма в ЖТФ, 47 (9), 51 (2021). DOI: 10.21883/PJTF.2021.19.51516.18879

[11] B. Dzuba, T. Nguyen, Y. Cao, R.E. Diaz, M.J. Manfra, O. Malis, J. Appl. Phys., 130 (10), 105702 (2021). DOI: $10.1063 / 5.0058154$

[12] S.A. Kukushkin, A.V. Osipov, J. Appl. Phys., 113 (2), 024909 (2013). DOI: 10.1063/1.4773343

[13] С.А. Кукушкин, Ш.Ш. Шарофидинов, ФТТ, 61 (12), 2338 (2019). DOI: 10.21883/FTT.2019.12.48549.51ks [S.A. Kukushkin, Sh.Sh. Sharofidinov, Phys. Solid State, 61 (12), 2342 (2019). DOI: 10.1134/S1063783419120254].

[14] Ш.Ш. Шарофидинов, С.А. Кукушкин, А.В. Редьков, А.С. Гращенко, А.В. Осипов, Письма в ЖТФ, 45 (14), 24 (2019). DOI: 10.21883/PJTF.2019.14.48018.17841 [Sh.Sh. Sharofidinov, S.A. Kukushkin, A.V. Red'kov, A.S. Grashchenko, A.V. Osipov, Tech. Phys. Lett., 45 (7), 711 (2019). DOI: 10.1134/S1063785019070277].

[15] S.A. Kukushkin, Sh.Sh. Sharofidinov, A.V. Osipov, A.V. Redkov, V.V. Kidalov, A.S. Grashchenko, I.P. Soshnikov, A.F. Dydenchuk, ECS J. Solid State Sci. Technol., 7 (9), P480 (2018). DOI: 10.1149/2.0191809jss

[16] A.V. Redkov, S.A. Kukushkin, Cryst. Growth Des., 20 (4), 2590 (2020). DOI: 10.1021/acs.cgd.9b01721

[17] S. Hernández, R. Cuscó, D. Pastor, L. Artús, K.P. O’Donnell, R.W. Martin, I.M. Watson, Y. Nanishi, E. Calleja, J. Appl. Phys., 98 (1), 013511 (2005). DOI: 10.1063/1.1940139

[18] S. Tripathy, S.J. Chua, P. Chen, Z.L. Miao, J. Appl. Phys., 92 (7), 3503 (2002). DOI: 10.1063/1.1502921

[19] Y.Y. Hervieu, J. Cryst. Growth, 568-569, 126187 (2021). DOI: $10.1016 /$ j.jcrysgro.2021.126187 